\title{
Bailar con el diablo: metamorfosis de una leyenda oral, del Abruzzo italiano a la literatura de cordel de Brasil ${ }^{1}$
}

\section{Dance with the devil: metamorphosis of an oral legend, from Italian culture found in Abruzzo to the cordel literature of Brasil}

\author{
Cruz CARrascosa PalOMERA \\ (Universidad de Chieti-Pescara) \\ cruz_carrascosa@hotmail.com \\ ORCID ID: 0000-0002-3627-7517
}

\begin{abstract}
This article presents different oral versions, for the most part unpublished, on the Dancing With the Devil legend. The author tries to outline, through a comparative analysis, the sequences and motifs found in this type of legend. The topic variants and the cultural basis have also been analysed in a legend of the Abruzzo region in Southern Italy, an ethological legend from Cape Verde, a chapbook (cordel) song from Brazil, an urban legend from Colombia and other international equivalents.
\end{abstract}

KEYWORDS: dancing with the Devil, the Devil's hooves, the Devil's blaze, abduction by the Devil, legends, oral literature, comparative literature.
RESUMEN. En este artículo se presentan diferentes versiones orales, en su mayor parte inéditas, de la leyenda Bailar con el diablo. El autor intenta delinear, mediante un análisis comparativo, las secuencias y motivos de este tipo de leyenda. También se comentan las variantes del tópico y sus sustratos culturales: una leyenda abrucesa, una leyenda etiológica caboverdiana, una canción de cordel brasileña, una leyenda urbana colombiana y otros paralelos internacionales.

PALABRAS-CLAVE: bailar con el diablo, pezuña del diablo, llamarada del diablo, rapto del diablo, leyenda, literatura oral, literatura comparada.

El 28 de febrero de 2009, Daniela Liberatore se encontraba en Roccamontepiano, pequeña localidad de la provincia de Chieti, en el Abruzzo italiano. Mientras conversaba con su abuela Clara Liberatore, ama de casa nacida en 1931 y originaria de aquel pueblo, Daniela grabó una leyenda, muy conocida en el lugar, sobre todo entre la gente de mayor edad, que tuvo la gentileza de comunicarme.

Las palabras de Clara, la narradora, transportan mágicamente a quien las escucha a los tiempos de «la adivina»: una mujer terriblemente hermosa que una noche convenció

\footnotetext{
${ }^{1}$ Agradezco a Clara Liberatore su versión abrucesa; a Daniela Liberatore por el cuidadoso trabajo de recolección, transcripción y traducción de etnotextos que ha llevado a cabo; a Horácio Santos por su versión caboverdiana; a Cecilia Santanché por su ayuda en la traducción al español de los textos brasileños y por sus consejos para la edición del texto en lengua original de Otávio Menezes; a Johnny Alexander Bautista por su versión colombiana; a Seif, anciano nuba, por su versión sudanesa; a José Luis Garrosa por su generosa aportación y sus correcciones; y a José Manuel Pedrosa por sus valiosas indicaciones teóricas, la importante aportación bibliográfica y todas las correcciones.
} 
a algunos vecinos de que acudiesen a comer cordero y a bailar a su casa durante el Miércoles de Ceniza. Un acto claramente impiadoso, incluso blasfemo, puesto que el Miércoles de Ceniza es la fecha de arranque de la Cuaresma y del ciclo penitencial del calendario.

Las ruinas de tal casa pueden verse aún en el centro del pueblo:

[Narradora] Bajo la iglesia hay una casita, en la parte de abajo. Entonces, vivía una moza y hacía todo... Se reunían, jóvenes, viejos. Estaba también tu abuelo... No, no, no... El abuelo de la tía Linuccia, tu abuela.

Entonces, el Miércoles de Ceniza..., esta muchacha hacía todas las noches los bailes, se bailaba... Entonces, el Miércoles de Ceniza, pues prepararon que tenían que comerse un cordero. ¡El Miércoles de Ceniza! Y quien sí quien no, insistieron en comerse el cordero.

Dice:

— ¡Mira, que hoy es pecado! ¡Aparece el diablo! ¡Es una cosa exagerada!

Y la muchacha:

- ¡No, no, no! ¡Lo hacemos! ¡Lo hacemos!

$\mathrm{Y}$ esta era una joven que te volvía loco de lo guapa que era. Entonces, prepararon la cena, comieron, empezaron a bailar... Todos los bailes de antes: quatriglie, scopa ${ }^{2} \ldots$ Todos estos bailes que se hacían... antiguos.

A un cierto punto empiezan a ver todos cosas que ya no eran normales: se quedaban a oscuras, se... Luego volvía la luz. A un cierto punto, dice..., cuando estaban bailando todos juntos. Mientras estaban bailando, aparece una llamarada. Apareció un joven, que era de una belleza de no creérselo y mientras el baile... Y empezó a bailar con este, con el otro: dejaba a uno, cogía a otro.

De repente, este joven empezó a transformarse, de guapo que era, se hizo más... Ya no era normal. Le vieron los pies... Cuando le vieron los pies, todos empezaron a echarse para atrás. El joven hizo aparecer una llamarada y desapareció. Los pies los tenía... eh... como un... eh, ¿cómo se dice? Como una cesta, redondos, como pezuñas... Algo no normal. ¡Pero él era de una belleza de no creérselo, de lo guapo que era este joven!

Después, todos, el día después, las cosas... Esta casa se hundió, se derrumbó. ¿Sabes dónde estaba esta casa? ¿Ves el centro social? ¿Está aquel árbol, aquella encina grande? Allí. Pues, si ves la encina, en la parte de abajo hay un hueco, hay un... trozo de muro, y debajo hay un poco de tierra que se araba antes. Justo ahí estaba. Ha quedado esta casita al final de la calle.

[Colectora] La maestra Palmina dijo que había uno, que quizás todavía vive, que lo vio. ¿Quién es este?

[Narr.] Sé que estaba el abuelo de... de tu abuela Linuccia que lo contaba... A nosotros nos lo contaba la abuela, la madre de mi madre.

Entonces, el día después todo el mundo allí a ver, y eso, pero ya no había nada. Se veía nada más que un trocito de muro porque el resto se había hundido.

[Col.] ¿Y los que estaban allí murieron?

[Narr.] Eeh... todos, todos los que fueron, que huyeron, se fueron. Pero muertos... Ahora no sé si todavía viva alguno. ¡Pero esa que era una joven... ! «La adivina» le decían.

He aquí la versión original, en dialecto de Roccamontepiano, del mismo relato:

[Narratrice] Sotto alla chiesa ci sta una casetta, a parta sotto. Allora, ci abitava una ragazza e faceva tutt... compagnia, i giovani, anziani. Ci stava anche tuo nonno... no, no, no... il nonno di Zia Linuccia, tua nonna.

\footnotetext{
${ }^{2}$ Bailes populares de Abruzzo que se realizan en grupo.
} 
Allora, il giorno delle Ceneri..., questa faceva tutte le sere i balli, si ballava... Allora, il giorno delle Ceneri, allora hanno preparato che dovevano mangiare l'agnello. Le Ceneri! E chi scì chi no, hanno insistito di mangiare st'agnello.

Dice:

- Guarda, che oggi è peccato! Comparisce il diavolo! È una cosa troppo esagerata!

E la ragazza:

-No, no, no! Si fa, si fa!

E quest ca ere una giovane che ti faceva impazzire per quant che era bella. Allora hanno preparato la cena, hanno mangiato, hanno cominciato a ballare... Tutti balli di prima: quatriglie, scopa,... Tutti sti balli che si faceva... antichi.

A nu certo momende, hanno cominciato a vedere tutte cose che non era più normale: si scuriva, si... diventava luce. A nu certo momende, dice..., stavano a preparare il ballo proprio tutti insieme. Mentre stavano a ballare è uscita una lampa di fuoco. È comparso un giovane, ma che era una bellezza da non credere, mentre a questo ballo..., e ha cominciato a ballare con quello, con quello: uno lasciava, uno prendeva.

Un bel momento, ha cominciato a cambiare questo giovane, da bello è diventato più... Non era più normale. Gli hanno guardato ai piedi... quando gli hanno guardato ai piedi, tutti quanti si so cominciati a tirare addietro. Lui ha fatto una lampa di fuoco è scomparso questo giovane. I piedi che ce li aveva.. ehm... come un... ehm, come si dice? Come na cesta, rotondi, come zoccoli... proprio una cosa non normale. Però che era una bellezza da non credere, per quando che era bello questo giovane.

Dopo, tutti quanti, il giorno dopo, le cose... questa casa se n'è scesa, se n'è caduta. Sai dove stava questa casa? Vedi sotto al centro sociale? C'è quell'albero, quella quercia grande? Là. Allora, se tu guardi a questa quercia, a parta sotto c'è un vuoto, c'è una... muraglio, e sotto c'è un pezzo di terreno che si zappava prima. Proprio là stava. È rimasta sta casetta sotto alla strada.

[Raccoglitrice] La maestra Palmina ha detto che ci stava uno, che forse è ancora in vita, che l'ha visto. Chi è questo qua?

[Narr.] Sacce che ci stava il nonno di... di nonna Linuccia che 1 raccundeve... A nu ce 1 araccundeva la nonna, la mamma di mamma.

Allora, il giorno dopo tutti quanti a vedere là, le cose, ma non esistiva più niente. Che si vedeva appena appena un pezzettino di muro perché se n'è sprofondato.

[Racc.] E quelli là si so morti quelli?

[Narr.] Eh... tutti, tutti quelli che sono andati, che hanno fuggito, se ne sono andati. Però di morti... Mo non lo so quanti ce ne so rimasti. Ma quella che era una giovane...! «La fata» gli dicevano.

En 1950 William Jones Wallrich publicó en la revista Western Folklore seis versiones en inglés de esta leyenda, que decidió titular The demon dancer, 'El demonio bailarín'. Estos relatos fueron recopilados por Wallrich en pequeños poblados de habla hispana del Valle de San Luis, al sur del Estado de Colorado.

Más de 40 años después, en 1992, Reidar Th. Christiansen en su catálogo tipológico de variantes noruegas, The migratory legends, clasificó este tema narrativo con el número 3070. The demon dancer, relacionándolo con el motivo folklórico-narrativo Q386.1. Devil punishes girl who loves to dance, 'El diablo castiga a la chica que le encanta bailar', catalogado por Stith Thompson en The Motif-Index of Folk-Literature (1955-1958).

Si observamos la leyenda abrucesa detenidamente e intentamos descomponerla en sus secuencias más básicas, conforme al catálogo de Stith Thompson, encontramos los siguientes motivos: 
1. G303.3.1.12.2. Devil as a beautiful young woman seduces man, 'El diablo en forma de hermosa joven seduce al hombre’. («La adivina», que es el primer personaje diabólico de la narración y realmente cumple un papel tan relevante como el diablo, seduce a los hombres para que violen la abstinencia de comer carne el primer día de Cuaresma y hagan el baile) $)^{3}$.

2. G303.6.2.1. Devil appears invisible among dancers, 'El diablo aparece inadvertido entre los bailarines ${ }^{4}$.

3. G303.4.5.4.1. Devil is betrayed by his goat hoofs, 'El diablo es descubierto por sus pezuñas de cabra's.

4. G303.17.2.5. Devil retreats into hell amid thunder and lightning, 'El diablo huye al infierno entre truenos y relámpagos ${ }^{\prime}$.

Esta leyenda abrucesa traslada una advertencia moral: se proclama testimonio de lo que le puede suceder a quien transgrede determinadas normas o tabúes (en este caso religiosos), y a quien se deja embelesar por la belleza de alguien desconocido y se abandona a los goces mundanos, abandonando para ello los deberes piadosos.

El relato de Clara Liberatore no puede dejar indiferente a ningún receptor, ya que, a pesar de no estar narrado en primera persona, asegura que fue experimentado por un pariente suyo que lo contó, la misma noche en que tuvo lugar el suceso, a quien más tarde lo transmitiría de viva voz a nuestra narradora.

Estas protestas de verdad histórica, que se hallan además arraigadas en las creencias religiosas que son tradicionales en este pequeño pueblo italiano, y que contribuyen a dar veracidad o al menos verosimilitud (en el plano de la emisión, la transmisión y la recepción) al relato dentro de su medio social, hacen que la aparición del diablo a los danzantes de Roccamontepiano tenga el estatus de suceso perfectamente creíble.

Se abre, así, un espacio de intersección con un fascinante elenco de creencias y narraciones populares, atestiguadas en muchas tradiciones del mundo, relativas a seres diabólicos, monstruosos o sobrenaturales, muchas veces femeninos, que son capaces de tomar contacto y a veces de seducir a sus víctimas antes de descubrir sus pies anómalos o monstruosos, con lo que queda revelada su anómala identidad ${ }^{7}$. Es sabido que el motivo folclórico de los pies extraordinarios del diablo se ha manifestado no solo en diferentes géneros de la literatura popular y de autor, sino que se ha propagado también a las más dispares expresiones artísticas: teatro, pintura, cine, comic, videojuegos.

Es el momento ahora de conocer la traducción al español de otro relato oral que fue registrado por mí mismo en portugués. El narrador fue Horácio Santos, célebre divulgador del patrimonio de la oralidad caboverdiana, a quien pude entrevistar en la

\footnotetext{
${ }^{3}$ Podríamos incluir de nuevo este primer motivo, con un hombre como seductor en lugar de una mujer, entre los motivos 2 y 3, cuando «el diablo seduce a todos con su danza». (Motivo relacionado con el G247. Witches dance, 'El baile de las brujas', y sus variantes).

${ }^{4}$ Motivo relacionado con el G303.10.4.0.1. Devil haunts dance halls, 'El diablo frecuenta las salas de baile'.

${ }^{5}$ Motivo relacionado con el G303.4.5.3. Devil has horse's foot, 'El diablo tiene pies de caballo'; el G303.4.5.3.1. Devil detected by his hoofs, 'El diablo descubierto por sus pezuñas' y el F517.1.6. Person with horse's hoofs, 'Persona con pezuñas de caballo'.

${ }^{6}$ Motivo relacionado con el G303.17.2.4. Devil and sinful priest disappear amid blaze of fire in the river, 'El diablo y un cura pecador desaparecen en una llamarada de fuego en el río' y el G303.17.2.7. Devil disappears amid terrible rattle, 'El diablo desaparece con una terrible sacudida'.

${ }^{7}$ Sobre el motivo de los seres sobrenaturales con pies o extremidades anómalos, véase Pedrosa (2001 y 2004) y Delpech (2004 y 2010).
} 
noche del 24 de septiembre de 2004 en el IV Encuentro de Narradores Orales «Palavras andarilhas» que se celebra anualmente en Beja, pequeña ciudad del Baixo Alentejo portugués.

El título que dio a esta leyenda Horácio Santos coincide con un conocido refrán caboverdiano, onde há criança, o diabo não para, es decir, 'donde hay un crío, el diablo no para' o 'donde hay un crío, el diablo no se queda'.

Había un baile en un pueblo a causa de un entierro, y el diablo se acicaló muchísimo y se puso sus mejores galas.

Este llegó al baile y se puso a bailar con la mujer más bella. Bailaron horas y horas y los dos permanecían perfectamente peinados y frescos como si nada. Todo el mundo estaba maravillado.

Un niño se asomó a la puerta del baile y se quedó mirando asombrado los pies de ese hombre tan apuesto. Miró y observó bien y al final, señalándolo con el dedo, gritó:

- iTiene pies de cabra!

El diablo agarró a la chica por la cintura y huyó con ella.

A las tres semanas, la chica apareció en una gruta. Olía mal, tenía toda la ropa rota y se había quedado muda.

Esta leyenda caboverdiana da cuenta (fabulosa, claro) del pavor que muchas tradiciones orales aseguran que siente el diablo ante los niños. La combinación de los motivos de la danza diabólica ${ }^{8}$ y del niño repelente de seres diabólicos está atestiguada en otras tradiciones de Hispanoamérica. En Bolivia, por ejemplo, ha sido registrada esta leyenda que habla de dos amigas a las que el diablo tienta con su danza: una se libra porque se protege con el llanto de un niño, mientras que la otra se va de fiesta con el diablo y desaparece para siempre:

Dice que había una chola que siempre a su compadre le decía:

-Ponte las lagañas del perro y vas a ver al diablo.

Y la otra chola se pone, y lo ve, que habrían danzas y se le aparece un hombre y le dice:

— ¿No quieres ir a bailar?

Y la chola le dijo:

-No me molestes.

Y fue adonde un padrecito y dijo:

- Ay, padrecito, se me aparece el diablo.

Entonces el padre le dijo:

-Reúne altas [sic] bebés y pellíscalos y mételos mote a la boca.

$Y$ al otro dijo:

-No, yo voy a terminar la fiesta al día siguiente.

La chola desapareció con sus cosas intacto y hasta ahora no se sabe nada9 .

El motivo narrativo del niño que sirve de talismán protector contra seres diabólicos y sobrenaturales en general es de viejo recorrido:

Harry Potter es, también, un típico puer senex (es decir, un niño sabio, un niño experto), y una criatura apotropaica (repelente de males), como lo fueron el Jesús que discutió con los doctores en Templo, o el Merlín britano que se enfrentó dialécticamente

\footnotetext{
${ }^{8}$ Sobre encontrarse con la muerte en el baile, véase Palleiro (1997); sobre bailarines endemoniados, véase Fradejas Lebrero (1998); y sobre danzas malditas en el medievo, véase Arcangeli (1992).

${ }^{9}$ Mihara (2004: 299).
} 
con los tres magos, o el heroico Ben-Sirá hebreo que debatió también con los sabios adultos, o, en el terreno de los heroísmos menos intelectuales y más deportivos, como lo fue el joven pero avispadísimo Jim Hawkins que se impuso a los amedrentadores piratas de The Treasure Island de Stevenson, o la tierna pero arrojada Dorothy de The Wizard of $O z$, a la que no había bruja que se le resistiera, o el menudo y providencial Short Round (Tapón) de Indiana Jones and the Temple of Doom... ${ }^{10}$

Pero, además, el relato caboverdiano contiene otros motivos narrativos de gran interés, al margen de los del baile maldito y el del niño protector contra el diablo. En su última frase, la de «a las tres semanas, la chica apareció en una gruta. Olía mal, tenía toda la ropa rota y se había quedado muda», están concentrados los motivos de:

-el ser sobrenatural que traslada y tiene prisionera en una cueva a una mujer a la que rapta; es un tópico que se halla bien presente en cuentos tan conocidos como el de Juan el Oso (Uther [2011], núm. 301: The Three Stolen Princesses, 'Las tres princesas raptadas');

-el mal olor del salvaje o transmitido o contaminado por el salvaje (véase MataCodesal [2018], con la amplia bibliografía que cita);

-la ropa rota como síntoma de pérdida de virginidad o de sufrimiento de una agresión sexual (véase Pedrosa, 2013);

-la mudez, o pérdida de la facultad del habla, como síntoma del estupor causado por el encuentro con un ser sobrenatural (véase Pedrosa, 2016).

La estructura de los motivos folclórico-narrativos que forman esta leyenda es la siguiente:

1. G303.3.1.2. The devil as a well-dressed gentleman, 'El diablo como un señor bien vestido'.

2. G303.6.2.1. Devil appears invisible among dancers, 'El diablo aparece inadvertido entre los bailarines'.

3. G303.4.5.4.1. Devil is betrayed by his goat hoofs, 'El diablo es descubierto por sus pezuñas de cabra'.

4. G303.9.5.6. Man temporarily abducted by devil, 'Hombre raptado temporalmente por el diablo,11.

5. G263.4.4. Witch makes person dumb, 'Bruja' deja mudas a las personas'.

Vemos que el esquema narrativo es muy similar al del relato anterior. En la leyenda caboverdiana de nuevo se realza la magnífica presencia del diablo, en este caso más por su elegancia que por su belleza. El diablo para transformarse, para ocultarse, se maquilla, y bailando encanta a todos los asistentes. El baile, en este caso, no representa en sí mismo un pecado de lujuria que conducirá a un nefasto final, sino que se celebra a causa de un funeral (práctica aún muy viva en muchas culturas bantús). Pero el diablo esta vez, al ser descubierto, no se limita a desaparecer, sino que se lleva consigo a la mujer con la que bailaba y ella más tarde aparece muda.

\footnotetext{
${ }^{10}$ Pedrosa (2008).

${ }^{11}$ Motivo relacionado con el G303.9.5.1. Devil abducts girl: has her hang about his neck and he flees to hell, 'El diablo rapta a una chica: la cuelga de su cuello y vuela al infierno' y el G442.2. Child-stealing demon, 'Demonio robaniños' y sus variantes.

${ }^{12}$ En nuestra narración el diablo ocupa el lugar de la bruja del motivo catalogado por Thompson.
} 
El rapto de personas a manos de seres diabólicos (brujas, monstruos,...) es otro motivo muy común y dinámico en las narrativas populares. Y que la persona secuestrada reaparezca muda o completamente trastornada es también un elemento recurrente en este tipo de historias.

En la literatura oral y en la música popular de Brasil goza desde hace décadas de cierta popularidad una composición musical cuyo título fluctúa, porque ha conocido actualizaciones y versiones diferentes, entre A história da moça que dançou com o diabo y A história da moça que dançou lambada com o diabo. Sus formas musicales son también plurales, y van desde la tradicional moda-de-viola hasta las cantilenas acompañantes de los folhetos de cordel. No hay, todavía, ningún estudio académico acerca de sus fuentes, génesis y fortuna popular y comercial, y los datos que he podido allegar proceden, básicamente, de carátulas de discos y de páginas más o menos informales de internet relacionadas con la música popular brasileña. También de YouTube, donde pueden ser escuchadas unas cuantas versiones y arreglos.

La primera noticia que tenemos es que A história da moça que dançou com o diabo fue una composición de Jayme Ramos y Teddy Vieira, que conocemos como «moda de viola clássica, em gravação Continental de 13 de abril de 1953, lançada em julho-agosto do mesmo ano sob número de disco 16782-A, matriz 11518. Reeditada com o selo Caboclo sob número CS-180-A». Es posible que fueran Ramos y Vieira los creadores de su letra y de su música, pero en los dominios de la literatura y la música popular nunca se puede estar del todo seguro. Cabe la posibilidad de que fueran también arreglistas, o de que se basaran o desarrollaran otras composiciones que anduvieran difundidas por la tradición oral. Hay muchas probabilidades de que la versión en verso que conocemos difundida a partir de 1953 estuviese a su vez basada e inspirada sobre leyendas y cuentos orales, en prosa, que podían llevar mucho tiempo circulando.

En torno a 1990 hubo una extraordinaria eclosión de composiciones que dieron continuidad a la popularísima tradición poético-musical de A história da moça que dançou com o diabo. Con la particularidad de que en muchas ocasiones se concretaba que lo que bailó aquella moza con el diablo fue la lambada, una danza popular brasileña cuyos orígenes suelen situarse en la década de 1970, aunque adquirió una difusión aún mayor, en Brasil y en todo el mundo, a finales de la década de 1980.

En el benemérito Portal de Literatura de Cordel (Projeto de Registro da Literatura de Cordel como Patrimônio Imaterial do Brasil) del Instituto de Estudios Brasileiros, <http://www.portaldocordel.ieb.usp.br>, tienen catalogadas estas nueve versiones (los títulos que se repiten es porque corresponden a ediciones o impresiones diferentes):

A moça que dançou a lambada com o cão

Cícero Carlos R. Duarte

s.d.

A moça, o cão e a lambada

Iris Tavares; Josenir Lacerda

1990

História da moça que dançou lambada com o diabo em Juazeiro

Otávio Menezes

1990 
A moça que dançou lambada com o satanás em Juazeiro do Norte Paulo de Tarso Bezerra Gomes (Paulo de Tarso) 1993

Lucilene, a moça que dançou lambada com o cão em Juazeiro do Norte Abraão Bezerra Batista 1990

A moca que bateu na mae e dançou lambada no inferno João Lucas Evangelista s.d.

A moca que bateu na mae e dançou lambada no inferno João Lucas Evangelista s.d.

História da moça que dançou lambada com o diabo em Juazeiro Otávio Menezes 1990

A moça que dançou lambada com o cão Paulo de Tarso Bezerra Gomes 1990

He aquí la traducción realizada por mí, y a continuación el texto en portugués, en 30 sextillas, del original mecanografiado y fechado en «Fortaleza 08/08/90», con la firma de «Otávio Menezes», que se puede consultar, en acceso libre, en la Cordelteca del Centro Nacional de Folclore e Cultura Popular de Brasil, <http://www.cnfcp.gov.br>:

Me contaron una historia que no podía creer.

Sin embargo, de esa misma historia otra persona vino a hablarme diciendo que era verdad y buena para versar.

Ahí yo dije: -Espera ahí, todo poeta mira a su alrededor, escucha la radio, lee el periódico, cuenta lo que admira, pero el poeta que es poeta, no va contando mentiras.

Porque el poeta retira su versión de la realidad y como versa para el pueblo, informando a la sociedad, no tiene que ir cambiando la mentira por la verdad. 
Sé que hay barbaridades versadas por el cordel por esas personas que inventan queriendo ser juglar, pero ahí es que cada uno responde por su papel.

Debe ser el más fiel el poeta cuando recrea. Solo decir la verdad de lo que el pueblo cuenta, no ir haciendo versos de los hechos que el pueblo crea.

Pero aquel mismo día me dijo otra amiga:

-Otávio, yo sé de un caso.

Un caso que me intriga y dijeron que era cierto. Dime si quieres que te lo diga.

Ella entonces hizo la higa ${ }^{13}$ con el pulgar de la mano y dijo: - Es una historia que bien merece atención porque causa escalofríos mucho miedo y asombro.

Entonces yo le dije a ella: - Cuenta ya tu tontería. Yo, por mí, no creo en historias de muertos, pues pienso que el asombro es cosa de cotillas.

Fue contando ella ligera y yo me quedé un poco desconfiado, preparando el pensamiento para aquel hecho travieso que decían que pasó allí en Novo Juazeiro.

En la ciudad del romero ${ }^{14}$, cierta noche esperada, una tal Conceição iba a una fiesta animada, una de esas fiestecitas modernas donde solo tocan lambada.

\footnotetext{
${ }^{13}$ Hizo un gesto con la mano simulando una higa, amuleto tradicional en forma de mano con el pulgar situado entre el índice y el dedo medio. Se hace para protegerse contra el mal de ojo.

${ }^{14}$ Debido a la gran cantidad de peregrinos que atrae la figura de Padre Cícero Romão Batista a la ciudad de Juazeiro do Norte.
} 
Conceição estaba traviesa

y le gustaba pasear,

iba mucho a las fiestas, tertulias, forró ${ }^{15}$, recreos y donde había lambada, allí estaba ella en el medio.

Y para no hacer feo sin el ritmo de la gramola, y contonearse del mismo modo que muchos artistas se contonean, Conceição estaba hasta yendo a una escuela.

$\mathrm{Al}$ son de una radiola, entrando la madrugada, Maria da Conceição se quedaba levantada, ensayando todos los pasos que se dan en la lambada.

Como estaba bien afinada, bailarina de primera, no se perdía forró ni fiesta, samba caliente ni gafieira ${ }^{16}$. Donde ella iba, la lambada tronaba la noche entera.

Fue entonces un jueves que Maria da Conceição salió de allí de su casa. Fue a una animación pensando: «Voy a arrasar con la lambada en el salón».

En esa misma ocasión Conceição hincó los pies y dijo: - Les voy a mostrar lo que es la lambada. Quita a Luiz Gonzaga y pon a Carlos André.

Fue entonces que la mujer vio a un hermoso joven bailando también lambada dando los pasos normales, y si ella bailaba bien, él bailaba mejor.

15 Baile popular.

${ }^{16}$ Baile popular que se baila muy agarrado. 
Su traje era igual a los de un gran artista: sombrero negro en la cabeza, gafas oscuras en los ojos. El sujeto daba un show de lambada por la pista.

«No hay moza que resista», pensó esto Conceição y salió rodando para cogerlo de la mano. Y la lambada prendió fuego allí en aquel salón.

Ella se deslizaba por el suelo y se levantaba volando.

Ella se contoneaba, meciendo la cadera de arriba a abajo y se la apretaba también a la pareja restregándose.

Los dos apenas se rozaban, en esa danza moderna, pegados pecho con pecho, meciendo panza con panza. Conceição ya se preguntaba: «¿Este tío no se cansa?».

Y la pareja en la lambança ${ }^{17}$ promovía la pagodeira ${ }^{18}$, pero Maria da Conceição ya se sentía cansada y dijo: - Voy a salir aunque tú no quieras.

Ella dijo: -Es la primera vez que bailo aquí y he visto que tú eres caliente, bailas y te contoneas sin caerte, y si tú quieres ahora ya podemos salir.

- Hay un buen jardín allí, vamos para allá, allí podemos conversar y es más tranquilo que aquí. ¿Pero cuál es tu nombre? Dijo él: —Es Cafifá.

Ella entonces exclamó: ¡Ah,

${ }^{17}$ Palabra inventada, formada por la unión de las palabras: lambada y dança.

${ }^{18}$ Pagode: ritmo popular de samba. 
qué nombre interesante!

Un nombre tan diferente

en un hombre tan elegante.

Te mereces un beso,

pero no te confíes mucho.

Dijo él en ese instante:

-Tal vez no me merezcas.

Es mejor que la mocita

desde ahora me olvide.

Y se quitó las gafas

y el sombrero de la cabeza.

El joven en la cabeza

tenía un cuerno horrible,

los ojos eran de fuego

como los ojos del demonio.

Conceição se asustó

gritando por san Antonio.

Conceição pensó: «Es un sueño»,

pero el diablo dijo: —No es nada.

Solo he venido aquí a la tierra

para enseñar lambada

y ya he visto que tú estás

cien por cien preparada.

Y salió ella asustada

huyendo por el portón,

$y$ entonces desde esa noche

afirman que Conceição

nunca más bailó lambada

ni quiso saber de bailes.

$\mathrm{Y}$ es por eso que se dice

ahora en Juazeiro

y por todo Ceará

que esta danza infeliz

tiene su misma raíz

en el templo de la maldición.

$\mathrm{Y}$ ahora dice el pueblo

que esta tal lambada

fue una moda inventada

por la hija de un perro.

História da moça que dançou lambada com o diabo em Juazeiro. A história que o povo conta

Me contaram uma história

que eu não pude acreditar.

Porém, essa mesma história

outro alguém veio me falar 
dizendo que era verdade e boa pra se versar.

Aí eu disse: - Pera lá, todo poeta se vira, ouve rádio, lê jornal, conta caso que admira, mas poeta que é poeta, não sai contando mentira.

Porque o poeta retira sua versão da realidade e como versa pra o povo, informando a sociedade, não deve sair trocando mentira pela verdade.

Sei que tem barbaridades versadas pelo cordel por pessoas que inventam querendo ser menestrel, mas aí é que cada um responde por seu papel.

Deve ser o mais fiel o poeta quando recria. Só falar pela verdade do que o povo noticia, não sair fazendo verso dos fatos que o povo cria.

Mas naquele mesmo dia me falou outra amiga:

-Otávio, eu sei de um caso. Um caso que me intriga e disseram que é verdadeiro. Fale se quer que lhe diga.

Ela então fez uma figa com o polegar da mão e falou: - É uma história que bem merece atenção porque ela causa arrepio muito medo e assombração.

Eu disse pra ela então: - Conte lá a sua besteira. Eu por mim não acredito em histórias de caveira, pois penso que assombração é coisa de fofoqueira.

Foi contando ela ligeira 
e eu fiquei meio cabreiro, aprontando o pensamento pr'aquele fato brejeiro que diziam acontecera lá no Novo Juazeiro.

$\mathrm{Na}$ cidade do romeiro, em certa noite esperada, uma tal de Conceição ia a uma festa animada, dessas festinhas modernas onde só tocam lambada.

Conceição era danada e gostava de passeio, andava muito em festas, tertúlia, forró, recreio e onde tivesse lambada, lá estava ela no meio.

E para não fazer feio sem o ritimo ${ }^{19}$ da vitrola, rebolar do mesmo jeito que muito artista rebola, Conceição tinha até frequentado uma escola.

Ao som de uma radiola, entrando na madrugada, Maria da Conceição ficava a noite acordada treinando todos os passos que se dança na lambada.

Ficando bem afiada dançarina de primeira, não perdia forró e festa, samba quente e gafieira. Onde ela ia, a lambada troava a noite inteira.

Foi então numa sexta-feira que Maria da Conceição saiu lá de sua casa. Foi pra uma animação pensando: «Eu vou arasar com lambada no salão».

Nessa mesma ocasião Conceição fincou pé e disse: - Eu vou mostrar

19 'Ritmo'. 
a lambada o que é.

Retira Luiz Gonzaga

e bota o Carlos André.

Foi aí que a mulher viu um belo rapaz dançando também lambada dentro dos passos normais, e se ela dançava bem, ele dançava bem mais.

Seus trajes eram iguais aos de um grande artista: chapéu preto na cabeça, óculos escuros na vista. O sujeito dava um show de lambada pela pista.

«Não há moça que resista», pensou assim Conceição e saiu rodopiando pra alcançar a sua mão. E a lambada pegou fogo ali naquele salão.

Ele rolava no chão e levantava voando. Ela fazia um molejo, penerava requebrando e tinha também um pega do casal se esfregando.

Os dois só se roçando naquela moderna dança, colando peito com peito, mexendo pança com pança. Conceição já perguntava: «Esse cara não se cansa?».

E o casal na lambança promovia a pagodeira, mas Maria da Conceição já apresentava canseira e disse: - Eu vou sair mesmo que você não queira.

Ela disse: -É a primeira vez que eu danço aqui e eu ví que você é quente, dança e roda sem cair, e se você quiser agora a gente pode sair. 
- Tem um bom jardim ali, vamos logo para lá, ali a gente conversa e é mais calmo do que cá. Mas como é o seu nome? Disse ele: —É Cafifá.

Ela então exclamou: - Ah, que nome interessante! Um nome tão diferente num homem tão elegante. Você merece é um beijo, mas não fique confiante.

Disse ele nesse instante: - Talvez não me mereça. È melhor que a mocinha desde logo me esqueça. E retirou os seus óculos e o chapéu da cabeça.

O tal rapaz na cabeça tinha um chifre medonho, os olhos eram de fogo como os olhos do demônio. Conceição apavorou-se gritando por Santo Antonio.

Conceição pensou: «É sonho», mas o diabo disse: -É nada. Eu só vim aqui na terra para ensinar lambada e já vi que você está cem por cento preparada.

E saiu ela assustada fugindo pelo portão, e então desde essa noite afirmam que Conceição nunca mais dançou lambada nem quiz ${ }^{20}$ saber de salão.

É por isso que se diz agora em Juazeiro e pelo Ceará inteiro que esta dança infeliz tem mesmo a sua raiz no templo da maldição. E agora diz o povão que esta tal de lambada foi uma moda inventada

20 'Quis', $3^{\mathrm{a}}$ persona, singular del verbo querer. 
por uma filha do cão ${ }^{21}$.

Para que podamos apreciar la energía que sigue moviendo la riquísima literatura de cordel brasileña, voy ahora a fijarme en otra composición, esta vez de Sherney Pereira, trovador de cordel muy conocido y reconocido en su género, que fue publicada también en 1990, con el título de A história da moça que dançou lambada com o diabo.

Esta canción narrativa, elaborada por un autor letrado pero en un marco y en un estilo de tipo popular, está compuesta por 73 sextillas. Traduzco del original brasileño (no ofreceremos la versión original sin permiso del autor):

Lectores, yo voy a contar un episodio macabro que pasó el otro día en el sertão $o^{22}$ de Jeremoabo, de la mocita que bailó la lambada con el diablo.

Esta historia sucedió en el sertão de Bahía. Era Sábado de Aleluya, el poblado se divertía, jarana por todos lados, mucho licor y alegría.

Iba a haber quema de Judas, la ciudad estaba animada, testamentos divertidos, la plaza toda adornada, estaba todo preparado para la noche de lambada.

El alcalde de la ciudad aprovechó la ocasión, lanzó un concurso público, llamó la atención del pueblo, para la pareja más lambadera tenía montones de premios.

El pueblo estaba eufórico, solo esperando el momento, las mocitas alteradas morían de contentamiento, aguardaban el concurso para mostrar el talento.

A un lado de la ciudad, en un barrio bien apartado, había una familia pobre de un sujeto denodado

${ }^{21}$ Otávio Menezes (1990).

${ }^{22}$ Región agreste poco poblada del interior de Brasil. 
de nombre Zacarías, por todos considerado.

Zacarías era mozo pobre pero tenía gran concepto y era conservador, hombre de mucho respeto. Los hijos bien educados vivían del mismo modo.

Los muchachos trabajaban para ayudar al sustento, las muchachas estudiaban con el profesor José Bento. En aquella casa sencilla no había sufrimiento.

La familia de Zacarías vivía allí sin problemas, su hija más jovencita se llamaba Iracema, moza sencilla y pacata y obediente del sistema.

Los hijos de Zacarías ya estaban emancipados, Iracema por ser menor necesitaba cuidados. Era una moza bonita de cabellos enrubiados.

En el calor de la juventud andaba toda excitante, bajo el control de los padres en esta fase preocupante. Era una moza perfecta, perfumada y elegante.

Cuando iba al mercado solo salía acompañada, doña Alzira, su madre, cuidadosa y preocupada, pues no le gustaría ver a su hija molestada.

En aquel día de fiesta la moza se despertó pronto, con la cabeza inclinada el día entero pasó, quería bailar lambada, todo bien planeó.

Iracema ahora estaba 
delante de aquel problema, tenía que ir a la fiesta, si el viejo no la dejase, iría de cualquier manera, costase lo que costase.

Ya a la hora del almuerzo todo el mundo reunido, Iracema tomó coraje y de modo decidido, dijo directamente: -Papá, voy a pedirte una cosa.

Dijo el viejo Zacarías: -Hija mía, dime. La petición siendo justa, concederé con mucho placer, pide ya de una vez para ver si lo puedo atender.

Con el cabello suelto parecía una princesa, tenía los labios carnosos, era una vestal de belleza. Su madre y sus hermanos allí sentados a la mesa.

Iracema dijo al viejo: -Papá, pido por caridad. En esta petición que hago, no hay ninguna maldad. Déjame que baile lambada mientras quiera mi voluntad.

- Hace mucho tiempo que yo espero este gran día, al mundo quiero mostrar toda esta energía.

Un concurso de lambada nunca fue grosería.

Luego después que la hija habló con garra y altivez, Zacarías se puso de pie sin perder la sensatez, dijo: - Tú ya has hablado, ahora llegó mi vez.

- Iracema, yo no estoy tan loco para permitir que vayas a esta fiesta. No hace falta insistir, no voy a dejarte a ti 
andando suelta por ahí.

- La lambada es danza fea y nunca fue cosa seria, es invención del demonio, solo trae pecado y miseria, es mujer mostrando el culo, dando gusto a la materia.

-No estás viendo, Iracema, que no te voy a dejar, hija mía, ir desenfrenada, por el mundo tonteando. Tu petición es un absurdo que jamás voy a aceptar.

La moza muy nerviosa ante aquella decisión echaba espuma de la rabia, golpeó firme con el pie el suelo, llorando se lamentaba:

— $\mathrm{OH}$, vida triste de perro!

-Para qué vivir esta vida como una esclava encadenada, diecisiete años de edad, no tengo derecho a nada, los celos de este viejales ya es una cosa atrasada.

- Si le pido con amor ir a cualquier lugar, nervioso y contrariado empieza a predicar:

«Vive siguiendo mis pasos!» No me deja respirar.

A aquella cena horrorosa toda la familia asistió.

Temiendo algo más grave doña Alzira interfirió: — ¡Niña, muestra respeto! Igualmente ella insistió

-Este viejo no entiende que hoy todo es moderno, que nadie puede vivir en este sufrimiento eterno. Hoy yo bailo lambada aunque sea en el infierno.

Dijo la vieja: - Hija, tú no sabes lo que haces. 
Dios protege a los hijos que obedecen a sus padres. La lambada es cosa fea, es invención de Satanás.

-Madre, deja de ser boba, dijo ella, contrariada: - Tú eres tonta y aburrida, tú no sabes de nada, mucho peor que papá que vive dando la lata.

— Vosotros sois dos idiotas que viven en el atraso, víctimas de la ignorancia, estáis vivos por caso, distantes de la realidad tratáis todo con descuido.

Iracema blasfemaba lamentándose de la vida, daba golpes en la pared, estaba muy abatida, lloraba que daba pena, como una pantera herida.

Encerrada en el cuarto pasó el resto del día, nerviosa, desesperada vivió ella su agonía, solamente la levantó la hora del ave María.

Cuando las campanas tocaron anunciando el anochecer, Iracema saltó de la cama, diciendo: - ¡Ahora van a ver! Aunque sea en el infierno, ahora me van a ver.

Se sintió más animada y delante del espejo se puso una falda corta por encima de la rodilla. Para bailar la lambada no escuchaba consejos.

Espió por la ventana y vio allí en la calle gente que iba y venía, la ciudad alborotada, tantos jóvenes hermosos, dejó a la joven alterada. 
-Yo voy a este concurso,

de lo contrario me acabo.

Voy a bailar la noche entera, bailo hasta con el diablo, suceda lo que suceda, aunque la puerca tuerza el rabo.

- Voy a salir a escondidas contrariando a mis padres, huiré por la ventana pues soy bastante sagaz. Mañana será otro día, todo estará en paz.

Iracema en aquella hora deprisa se arregló, sin percibir el peligro hizo lo que pensó, huyó sin ser percibida y para la fiesta tiró.

Caminaba por la calzada con un bolsito a un lado, pensando solo en la lambada, en el momento tan soñado, de repente, lo percibió, un coche estacionado.

Era un escarabajo todo negro en la esquina del mercado, estaba allí, al volante, un hombre de mala pinta, era feo y ceñudo, de cabello ensortijado.

La moza se aproximó con aires de solterona, el hombre bajó del coche y fue diciendo: — ¡Eh, señora! Yo también voy a la lambada, puedo llevarte en coche.

Iracema en aquel instante aún vaciló en aceptar, pero como estaba cansada, prefirió no rehusar, dijo al hombre: - Yo acepto, sin demora vamos allá.

El negrazo todo contento en aquel exacto momento, sin decir una sola palabra, 
puso el coche en movimiento, salió montando barullo, corriendo más que el viento.

Por las calles de la ciudad mientras el escarabajo corría en el tocadiscos del coche una lambada se oía.

Ahora iba sin prisa con el son se divertía.

El automóvil corría a alta velocidad y el negro resabiado, usando la sagacidad, se fue a la periferia, abandonando la ciudad.

Iracema se distraía con la música envolvente sin siquiera percibir la traición de la serpiente. El coche veloz seguía por un camino diferente.

Solo fue a descubrir la terrible situación cuando sintió que el coche iba en otra dirección. Entonces tuvo miedo, casi murió de aflicción.

Creyó que era cosa ruin y a Dios pidió clemencia, el negrazo pisaba a fondo y fumaba con frecuencia, Iracema estaba pagando por su desobediencia.

Fue aquí que la doncella conoció la realidad, estaba siendo tragada por su propia vanidad, solo Dios poderoso podía librarla de este mal.

Pensó en pedir al hombre que la llevase a casa, a pesar de la noche fría su rostro era una brasa, el escarabajo corría tanto como si tuviese alas. 
El son fuerte y ruidoso del tocadiscos salía, el negrazo siempre callado su camino seguía, Iracema de tanto miedo, cada vez más se encogía.

La lluvia caía fuerte que hasta parecía invierno, el tocadiscos no paraba de tocar un son moderno, Iracema leyó en una placa: «Bienvenido al infierno».

Fue a esta hora difícil cuando la muchacha despertó y lloró arrepentida de las bobadas que habló, el infierno que ella pidió, estaba allí, delante de ella.

Lloraba que ni un crío y llamaba a sus padres, estaba muy distante, nadie oía sus ayes, entraría en el infierno en compañía de Satanás.

Era medianoche en punto cuando el escarabajo entró en una especie de poblado, Iracema se asustó, una cruz y una calavera en la entrada avistó.

El negrazo paró el coche al lado de un taller y habló de esta manera: - ¿Estás satisfecha, chica? El infierno es todo tuyo, puedes cumplir tu destino.

En aquel lugar extraño era todo confusión, un alboroto infernal, sosiego no había, no, era gente que vivía en un desorden de fieras.

La gente allí no paraba, era tremenda la lucha, igual que un campo de guerra, solo violencia y disputa, 
gritos de dolor y desesperación resonaban de una gruta.

A un castillo bien antiguo Iracema fue llevada, había allí una bacanal, hasta mujeres peladas, la negrada se divertía al ritmo de una lambada.

Iracema muy nerviosa ni se tenía de pie, sin demora preguntó:

—Dime quién eres tú. El negrazo dijo: - El diablo, conocido como Lucifer.

Cogió a la joven por el brazo con la fuerza de un león, Iracema dijo enfadada: - Ten más educación, me estás haciendo daño, ¡so cara de tizón!

Percibiendo que a la moza no le gustó la broma, el diablo se puso nerviso y berreó de esta manera: - iCierra la boca, so guarra, deja de montar jaleo!

- No estás tan buena y tampoco eres enjuta, vas a tener que aguantarme a base de fuerza bruta, voy a esmerarme en bailar para ver tu conducta.

La falda corta de la moza subía junto a la polvareda, esqueletos requebraban cerca de una chimenea, el cojuelo estaba animado bailando con una calavera.

El diablo desatado no dejaba a la infeliz, la cogía por debajo resoplando por la nariz y decía gruñendo:

- Hoy yo te hago feliz.

Casi muerta de cansancio 
y sufriendo la humillación, Iracema dijo al demonio:

-Yo no aguanto más, no. Subía una peste mala del sobaco del negrazo.

El fuerte hedor de azufre que exhalaba aquella sala, ahogaba a cualquier mortal y la moza casi sin habla giraba que ni una peonza, más veloz que una bala.

Era ya madrugada así que el gallo cantó, Iracema no soportando los malos tratos, se desmayó, parecía desvalida cuando alguien la encontró.

Estaba a la orilla del camino tirada en un escondrijo, andrajosa, toda inmunda, sin coraje y sin moverse, fue más tarde encontrada por un conductor de camión.

Abatida y desconsolada ella le pidió suplicante que la llevase para casa y en aquel mismo instante, el camionero así hizo porque no era arrogante.

Con mucha satisfacción Iracema fue recibida, pidió perdón a su madre llorando arrepentida, abrazó a sus hermanos en una alegría incontenida.

Fue a hablar con su padre llorando perdidamente y juró entre sollozos nunca más ser imprudente, pues Dios jamás lo bendice al hijo desobediente.

Aquí termino la historia que según un viajante sucedió con certeza en aquel sertão distante.

Si no pude ser más exacto, 
creo que narré el hecho

de una manera elegante.

El poema del extraordinario cordelista Pereira es un óptimo ejemplo de lo sofisticado y valioso de la literatura de cordel brasileña del siglo XX, porque contiene rasgos fundamentales, magistralmente reciclados, de su género: narra hechos supuestamente históricos y reactiva con gran eficacia viejos tópicos propios de la literatura popular.

La composición en su conjunto transmite un mensaje admonitorio, moralizante: alaba la unión entre los miembros de la familia, la obediencia a los mayores y el respeto a las normas sociales y religiosas como estrategia mejor para quedar a salvo de los peligros del mundo.

El poema para pliego de cordel de Pereira tiene un desarrollo novelesco muy notable y creativo, y combina y amplifica motivos narrativos procedentes de temas y tradiciones diversas. Pero no es difícil reconocer, entre ellos, unos cuantos de los más característicos de la leyenda que, desde que analizamos la versión abrucesa, estamos analizando: entre ellos está el baile nocturno de una danza tenida por procaz y deshonesta, la prohibición de bailar a Iracema, el deseo irrefrenable de ella por bailar, la invocación al diablo, el rapto de la joven, la danza frenética, el abandono de la víctima...

Solo me resta decir, a propósito de la tradición de estos tópicos en Brasil, que existe hasta un cortometraje, A moça que dançou com o diabo, filmado por el Grupo Kino-Olho, de Rio Claro, que llegó a recibir la Mención Especial del Jurado en el $69^{\circ}$ Festival de Cine de Cannes, en el año 2016. Estoy seguro, conociendo la popularidad del tema en Brasil, de que no será el único ni el último reciclaje audiovisual de A moça que dançou com o diabo.

Hasta aquí nuestro análisis se ha fijado sobre todo en un relato del Abruzzo italiano, en otro de Cabo Verde y en uno de Brasil. Pero lo cierto es que esta leyenda ha sido muchas veces atestiguada en otros lugares de la geografía panhispánica, y en español. De hecho, goza de gran difusión en gran parte del continente, desde México a Argentina.

He aquí una versión más que vamos a conocer. El 12 de mayo de 2009, Jhonny Alexander Bautista, joven de 26 años y oriundo de Santiago de Cali, en el Departamento del Valle del Cauca, en la región andina de Colombia, me contó en Roma la siguiente leyenda, muy conocida, me dijo, en su ciudad:

Hay una discoteca cerca de Cali, El Juanchito. Ahí va la gente a bailar salsa, mucha salsa, mucha salsa. Es un lugar de mucha perdición, ¿sabes? Mujeres, bailar, todo, ¿sabes?

Pues una vez, ahí la gente estaba bailando. Había una mujer muy guapa, todos querían bailar con ella, era la más guapa. Pues a las doce de la noche se le volvieron los pies de cabra. La gente lo vio y decían:

- ¡Mira! ¡Tiene los pies de cabra! ¡Es el diablo!

Entonces, todo el mundo se separó de ella. Ella se puso a correr, y escapó por una ventana. Así. Había mucho humo. No se veía bien.

Creo que mi tío estaba ahí esa noche y lo vio.

Salió en el periódico y todo, la gente que lo contaba.

Eso pasó ahí porque es un lugar de mucha perdición, ¿sabes?

La historia caleña se desarrolla mientras se baila en una discoteca (lugar de perdición) y el diablo, transformado en una mujer hermosa, muestra sus pezuñas a medianoche y desaparece envuelto por el humo a través de una ventana. 
Es, evidentemente, una versión mucho más breve y menos rica que la brasileña. Pero tiene puntos de gran interés poético. En especial sus estrategias de protesta de verosimilitud. En este caso, el narrador dice no solo conocer a una persona, un tío suyo, que estaba presente mientras se desarrollaba el acontecimiento descrito, sino que asegura además que la noticia llegó a publicarse en el periódico. Otro lugar bastante común de las leyendas urbanas.

La brevedad y concentración de la versión colombiana nos permite, por otro lado, confirmar la relevancia de los motivos del diablo que se presenta como bailarín y de sus característicos pies animales. Tópicos centrales en una gran cantidad de versiones.

Aunque podría seguir trayendo a colación muchas más versiones del relato de Bailar con el diablo que han sido documentados en otras tradiciones, prefiero cerrar esta monografía acordándome de algunos otros relatos, de arraigo pluricultural, que no incorporan el motivo del baile con el diablo, pero sí el del encuentro con un ser sobrenatural que tiene extremidades anómalas, propias de los seres del infierno.

En esta versión marroquí comprobamos cómo la muy tradicional Aixa Kandixa, aquí una despiadada ondina que ahoga a los hombres que la siguen al río, es también reconocible por sus pezuñas:

\section{La mujer encantada que ahoga a los hombres}

Es Aixa kandixa una seductora mujer encantada que habita en los ríos de ocultas orillas y aparece en los lugares alejados, ofreciendo agua al caminante solitario. Se casa con todos los hombres con quienes se encuentra y le gustan. Al querer poseerlos los atrae con dulces insinuaciones hasta subyugarlos, obligándoles a seguirla hasta el río que habita, donde los ahoga. Se la conoce por sus pies en forma de pezuña y por los largos dedos de sus manos delicadas ${ }^{23}$.

Termino con el escalofriante relato que contó Seif, un anciano nuba del centro de Sudán, el 5 de enero de 2004, en una jornada de trabajo de campo que se desarrolló en Vallecas (Madrid):

En Sawakem, significa 'la zona donde vive el yin', sucedió algo extraño a un hombre que me contó esta historia en el Puerto de Sudán.

Un hombre conducía y le pareció ver reflejos o imágenes de gente, se detuvo, pero no vio nada. Un poco después le pareció ver un caballo cruzar la calle, al acercarse más, vio que era un hombre con patas de caballo. Siguió conduciendo hasta que se encontró con alguien y pudo contar lo que vio. El hombre con el que hablaba le preguntó cómo eran esas patas y le mostró las suyas diciendo:

— ¿Cómo estás?

Entonces el conductor vio horrorizado que ese hombre también tenía patas de cabra. Subió al coche y salió huyendo.

La lista de diablos danzantes y de otros seres sobrenaturales y con pies y piernas extravagantes, encarnaciones del mal que tienen encuentros sorpresivos con los humanos, podría hacerse interminable, puesto que se halla difundida más allá de cualquier frontera geográfica, cronológica, lingüística, cultural, de género literario... Y puesto que está todavía en proceso constante de renovación y actualización.

El tipo narrativo de Bailar con el diablo y el tipo narrativo de El ser sobrenatural con pies o piernas anómalos, que muestran una tendencia pertinaz a combinarse y a

\footnotetext{
${ }^{23}$ Ibn Azzuz Akim (1958: 8).
} 
formar un tipo híbrido, han tenido, por separado y juntos, evoluciones fascinantes. En investigaciones futuras espero poder seguir dando cuenta de ellas. Por el momento, el desvelamiento de estas nuevas versiones, y las reflexiones sobre su tradición común, espero que contribuyan a iluminar parcelas todavía poco conocidas de la tradición narrativa oral panhispánica.

\section{BIBLIOGRAFÍA}

ARCANGELI, Alessandro (1992): «Dance and punishment», Dance Research, 10.2, pp. 3042. DOI: https://doi.org/10.2307/1290653

ChristiAnSEN, Reidar Th. (1992): The migratory legends. A proposed list of types with a systematic catalogue of the Norwegian variants, Helsinki, Suomalainen Tiedeakatemia, Academia Scientiarum Fennica.

DELPECH, François (2004): «En torno al diablo cojuelo: demonología y folklore», en $E l$ diablo en la Edad Moderna, Maria Tausiet y James Amelang (eds.), Madrid, Marcial Pons, pp. 99-131.

DELPECH, François (2010): «D'Asmodée au Diable Boiteux. Racines orientales et fonctions magiques d'un type folklorique», en Magie et divination dans les cultures de l'Orient: Actes du Colloque organisé par l'Institut du Proche-Orient Ancien du Collège de France, la Société Asiatique et le CNRS (UMR 7192) les 19 et 20 juin 2008, Paris, Collège de France, pp. 163-184.

FRADEJAS LEBRERO, José (1998): «Los bailarines irreverentes (dos pliegos sueltos)», Epos. Revista de Filología, XIV, Madrid, UNED, pp. 541-561.

DOI: https://doi.org/10.5944/epos.14.1998.10072

IBN AZZUZ AKIM, Mohammad (1958): Diccionario de supersticiones y mitos marroquíes, Madrid, CSIC.

Mata-CODESAL, Diana (2018): «El olor del cuerpo migrante en la ciudad desodorizada. Simbolismo olfativo en los procesos de clasificación social», AIBR. Revista de Antropología Iberoamericana, 13, pp. 23-43.

MENEZES, Otávio (1990): História da moça que dançou lambada com o diabo em Juazeiro. A história que o povo conta, Fortaleza. URL: <http://docvirt.com/docreader.net/DocReader.aspx?bib=cordel\&pagfis=60206>.

MinARA, Yukihisa (2004): Narrativas tradicionales del Dpto. de La Paz, Bolivia, Hirakata, Osaka, Japón, Seminario de Y. Mihara de la Universidad de Kansai Gaidai.

PALLEIRO, María Inés (1997): «El encuentro con la muerte a la salida del baile: entre la oralidad narrativa y la hipertextualidad mediática», en III Congreso latinoamericano de folklore del Mercosur: VII Jornadas nacionales de folklore, Buenos Aires, Instituto Nacional Superior del Profesorado de Folklore.

PedrosA, José Manuel (2001): «El diablo cojuelo en América y África: de las mitologías nativas a Rubén Darío, Nicolás Guillén y Miguel Littin», Rivista di Filologia e Letterature Ispaniche, 4, pp. 69-84.

Pedrosa, José Manuel (2004): «Versiones literarias del mito de El diablo cojo (Shakespeare, Goethe, Tolstoi, Kipling, Rego, Valle-Inclán, Cela, Galeano)», en La literatura en la literatura: Actas del XIV Simposio de la Sociedad Española de Literatura General y Comparada, edición de Magdalena León Gómez, Alcalá de Henares, Centro de Estudios Cervantinos, pp. 551-561. 
PedrosA, José Manuel (2008): «Harry Potter: la construcción y la deconstrucción de un héroe», Educación y Biblioteca 20:164, pp. 62-64. Disponible en internet, URL: $<$ http://www.cervantesvirtual.com/obra-visor/harry-potter-la-construccion-y-ladeconstruccion-de-un-heroe/html/db60c8b1-08ad-4fef-8c6ee389b455135f_2.html\#I_0_>.

PedrosA, José Manuel (2013): «Los zapatos rotos del Lazarillo de Tormes», Analecta Malacitana, 36, pp. 71-100.

PEDROSA, José Manuel (2016): «Estupor, locura, silencio, muerte: hacia una antropología comparada de las emociones fuertes», en Etnografías de la muerte en América Latina: Anales del Museo Nacional de Antropología XVIII, Francisco M. Gil y Patricia Alonseo Pajuelo (Coords.), Madrid, Ministerio de Educación, Cultura y Deporte, pp. 32-53.

PEREIRA, Sherney (1990): A história da moça que dançou lambada com o diabo, Ilhéus.

THOMPSON, Stith (1955-1958): Motif-Index of Folk-Literature: a Classification of Narrative Elements in Folktales, Ballads, Myths, Fables, Mediaeval Romances, Exempla, Fabliaux, Jest-Books and Local Legends. Ed. rev. y aum., Bloomington \& Indianapolis-Copenhague, Indiana University-Rosenkilde \& Bagger, 6 vols.

UTHER, Hans-Jörg (2011): The types of international folktales: a classification and bibliography based on the system of Antti Aarne and Stith Thompson, Helsinki, Suomalainen Tiedeakatemia, Academia Scientiarum Fennica.

WALLRICH, William Jones (1950): «Some variants of the "Demon Dancer"», Western Folklore, IX, n. 2, pp. 144-146. DOI: https://doi.org/10.2307/1496547

Fecha de recepción: 19 de marzo de 2019

Fecha de aceptación: 24 de mayo de 2019 